Chapter 4

\title{
The Use of GIS for Supporting the Experimental Representation of the Selected Supply Network in Pafos Municipality - 'The Hydrogis Lab'
}

\author{
Kyriacos Themistocleous, Ploutarchos Evlogimenos, \\ Athos Agapiou and Diofantos G. Hadjimitsis \\ Additional information is available at the end of the chapter
}

http://dx.doi.org/10.5772/59533

\section{Introduction}

The HydroGIS Lab project (http://cyprusremotesensing.com/hydrogis/) aims to satisfy the dire need for authorities to solve the extremely serious problem of water supply as a result of continued water shortage. The chronic problems of water losses in the water supply network pipes, the uncontrolled and non-optimum operation of pumping stations, the incorrect design of the networks because of various interventions such as town planning and erroneous mapping of existing networks, are some of the most important problems which need to be resolved in order to optimize the performance of the networks and, consequently, save water and energy. The innovative aspect of the Project is that state-of-the-art technologies are combined for the mapping of water networks through the Global Positioning System (GPS), Radar Scanners and Satellite Remote Sensing (SRS). The data is entered into a Geographic Information System (GIS), with the aim of developing a digital imprint and the mapping of the network. The study of an existing selected water supply network and the collection of the necessary information by the Cyprus University of Technology and the Water Development for the network and its systems will lead to an imaging of water pipes and their design using a radar scanner and special software and GIS. Satellite images, which have been transformed into the local reference system using specialized software, will be coupled with the digital imaging of the existing maps. This information will then be organized in such a way allowing the development of maps and their analysis at different levels (e.g. water supply network, buildings, water supply elements, geographic information, features of the network's systems, etc.). 
GIS has been used to develop a comprehensive management system of the information, including text, cartographic and quantitative data. Maps from Paphos Municipality depicting existing buildings, streets and other infrastructure were used in creating the digital map. The ground penetrating radar (GPR) provided imaging of all required information regarding the existing water supply pipes, including altitudes, grading, location of other services, diameters, etc. Satellite images of the region of Paphos Municipality will be used to retrieve the present conditions, such as current construction development and, therefore, the immediate water supply needs in the municipality.

\section{Methodology}

A representative section of the water supply network in the Pafos Municipality area, including pumping stations, reservoirs, valves, and flowmeters, were recorded and the selected network was digitized. The MALA GPR was used to conduct a survey of the existing water network. After the GPR survey was concluded, the GPR data were analyzed and the water pipes were identified, according to their diameter, material and depth. Following, each survey point was inserted into a GIS system, including all the data acquired. The network was then connected from each survey point.

The power of a GIS comes from the ability to correlate different information in a spatial context and to reach a conclusion about this relationship. All the retrieved information that were available through the acquired software regarding surveying, analysis, management, processing, were inserted in the GIS database. The GIS system is flexible, allowing the addition of any layer considered necessary for the better management of the Project information. The final structure and content of the digital imprint will depend on the results of the initial study of the networks in Paphos Municipality, in order to proceed with an accurate modeling of the representative network.

A methodology will be created for detecting and adapting critical parameters of the mathematical models (e.g. surface roughness coefficient of pipes etc.), based on actual experimental measurements of the flow field in corresponding hydraulic models. As well, detailed experimental verification of the computational results and the development of knowledge for selfregulation of pumps and valves will be examined in order to satisfy the supply needs in conjunction with the uniform pressure distribution in the water supply network. In this way, guidelines will be developed which could form the basis for developing a user-friendly network simulation software, able to make up for the lack of communication between the different sciences involved in developing, designing and managing water supply networks.

A framework was created to develop specifications and relevant computational tools for the optimum analysis of supply networks, both in the design and the operation phase. An optimization framework was defined, including the identification of the problem (determination of control variables and performance criteria) and its solution, using multicriteria evolution algorithms. This methodology will be utilized in the context of an information system for the management of networks, which will include a database, a GIS and a compu- 
tational code. In order to implement the computational code, existing tools and models will be used or new ones will be developed, so as to ensure compatibility with the proposed methodological framework.

The operation of the experimental model is studied in detail, with the support of specialized instruments and systems for the continuous recording of the variables (i.e. flow capacity, pressure, power etc) at different points in the network. The experimental results will be utilized for verifying the theoretical models as well as for developing a framework for the identification and optimum adaptation of critical parameters of the simulation models (e.g. surface roughness coefficients), based on the measurements in the corresponding hydraulic model. Furthermore, specialized analyses will be conducted in typical locations of the experimental model, which may prove to be problematic (e.g. cross-sections downstream and upstream of the pumping stations) in order to study flow phenomena (e.g. local losses at operational phases) and propose improvements.

\section{Ground-penetrating radar (GPR)}

Current research (Eyuboglu et al, 2004; Demirci et al., 2012; Gamba and Lossani, 2000) states there is a trend toward development of more and more sophisticated systems including the ground penetrating radar (GPR) technique, which is safe for use in urban environments and also protects the geological, environmental and archaeological integrity of subsurface settings (Gamba and Lossani, 2000). GRP is a geophysical method that uses radar pulses to image the subsurface. It is a nondestructive method that uses electromagnetic radiation in the microwave band of the radio spectrum, and detects the reflected signals from subsurface structures (Dong et al., 2012). GPR interpretation of this reflected energy may yield information on subsurface structural variation and condition of the pipeline, as indicated in figure 1.

GPR is also one of the most used tools in the field of the water monitoring and management especially in the fields of the drainage pipes detection and characterization, water leaks in pipe detection and determination of the time-behavior of water content in the soil (Allerd et al., 2008; Crocco et al.,2010; Lambot et al.,2008; Hadjimitsis et al., 2013). GPR can accurately pinpoint buried pipeline leaks without digging. The leaking substances can be identified at the source by the radar via the changes in the surrounding soil's electrical parameters. The GPR is able to generate 3D underground images of pipes, power, sewage and water mains. As well, it can identify leaks in buried water pipes either by detecting underground voids created by the leaking water as it erodes the material around the pipe, or by detecting anomalous change in the properties of the material around pipes due to water saturation. Unlike acoustic methods, application of ground penetrating radar for leak detection is independent of the pipe type (e.g., metal or plastic) (Eyuboglu et al, 2004). The principles involved are similar to reflection seismology, except that electromagnetic energy is used instead of acoustic energy, and reflections appear at boundaries with different dielectric constants instead of acoustic impedances. 


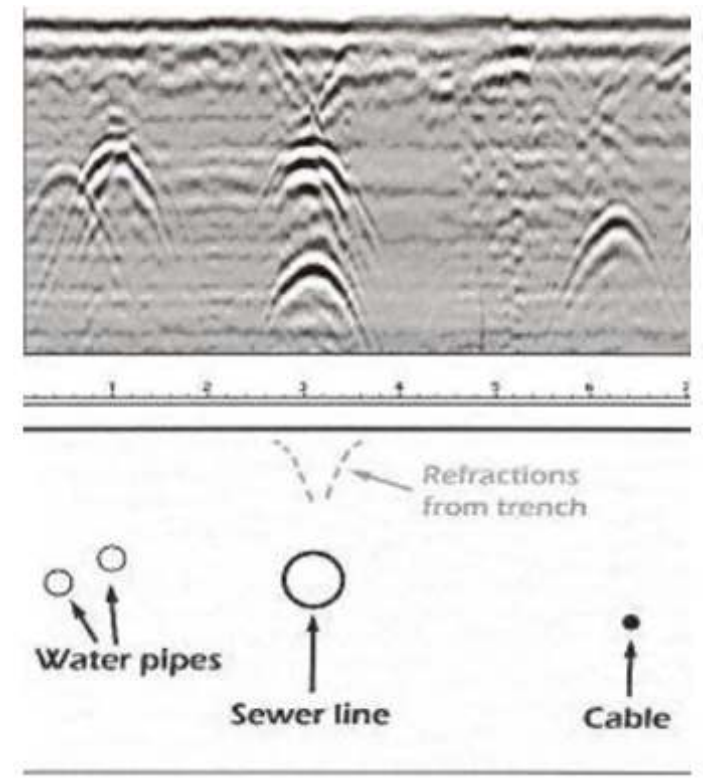

Figure 1. Reflected signals from subsurface structures

\section{Survey and GIS}

Paphos Municipality is one of the municipalities in Cyprus facing very serious problems with the water supply network, due to the age of the network, rapid town development and the expansion of the network in an unorganized manner. One of the aims of the HYDROGIS project is the study of an existing selected water supply network in the Municipality in an effort to understand the 'logic' of the network and select a representative part of it that will include almost all the components (i.e. pumping station, main piping, valves, flowmeters etc) present in the networks of the Municipality in order to conduct a comprehensive study. Therefore, the mapping and development of a database using GPS and GIS technologies, as featured in figure 2 , has the aim of developing a digital imprint of a representative water network in Paphos Municipality and the creation of scale modeling for detailed experimental studies.

A representative section of the water supply network in the Pafos Municipality area, all the features and systems which compose it, including pumping stations, reservoirs, valves, and flowmeters have been recorded and the selected network was digitized (Figure 3). A survey through the use of a latest technology radar scanner has been conducted. The specific radar scanner is a MALA ground penetrated radar designed for urban areas and background noise. The shielded antenna used consists of both transmitter and receiver antenna elements in a single housing. After the GPR survey was concluded, the GPR data were analyzed using the GroundVision 2 and RadExplorer software, where the pipes were identified, according to their diameter, material and depth. Following, each survey point was inserted into a GIS system, 
including all the data acquired. The network was then connected from each survey point, as indicated in Figure 4.

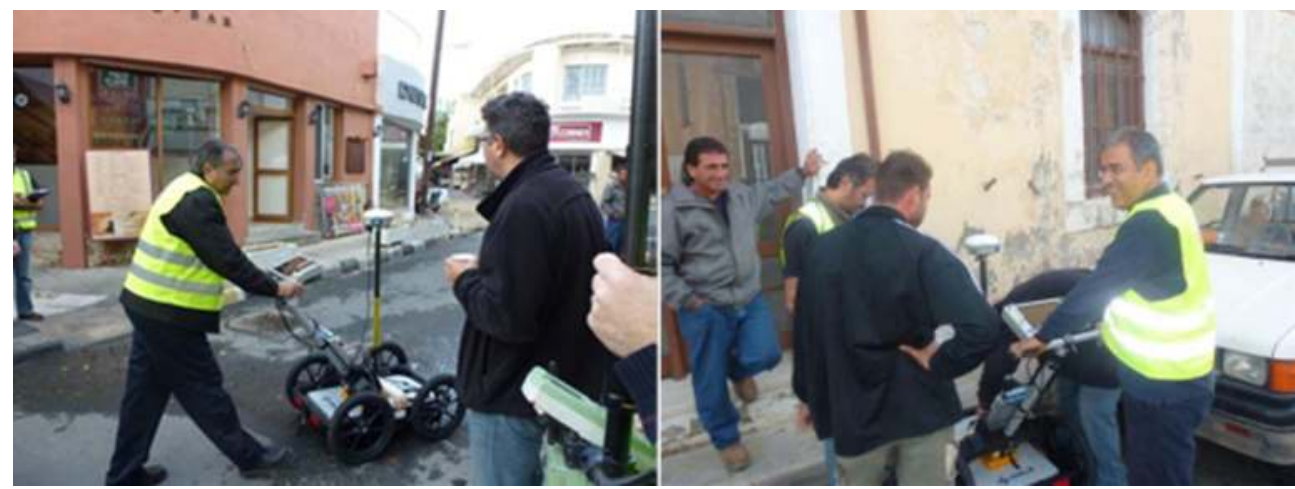

Figure 2. Geo-radar Scanning of the Paphos water utility network
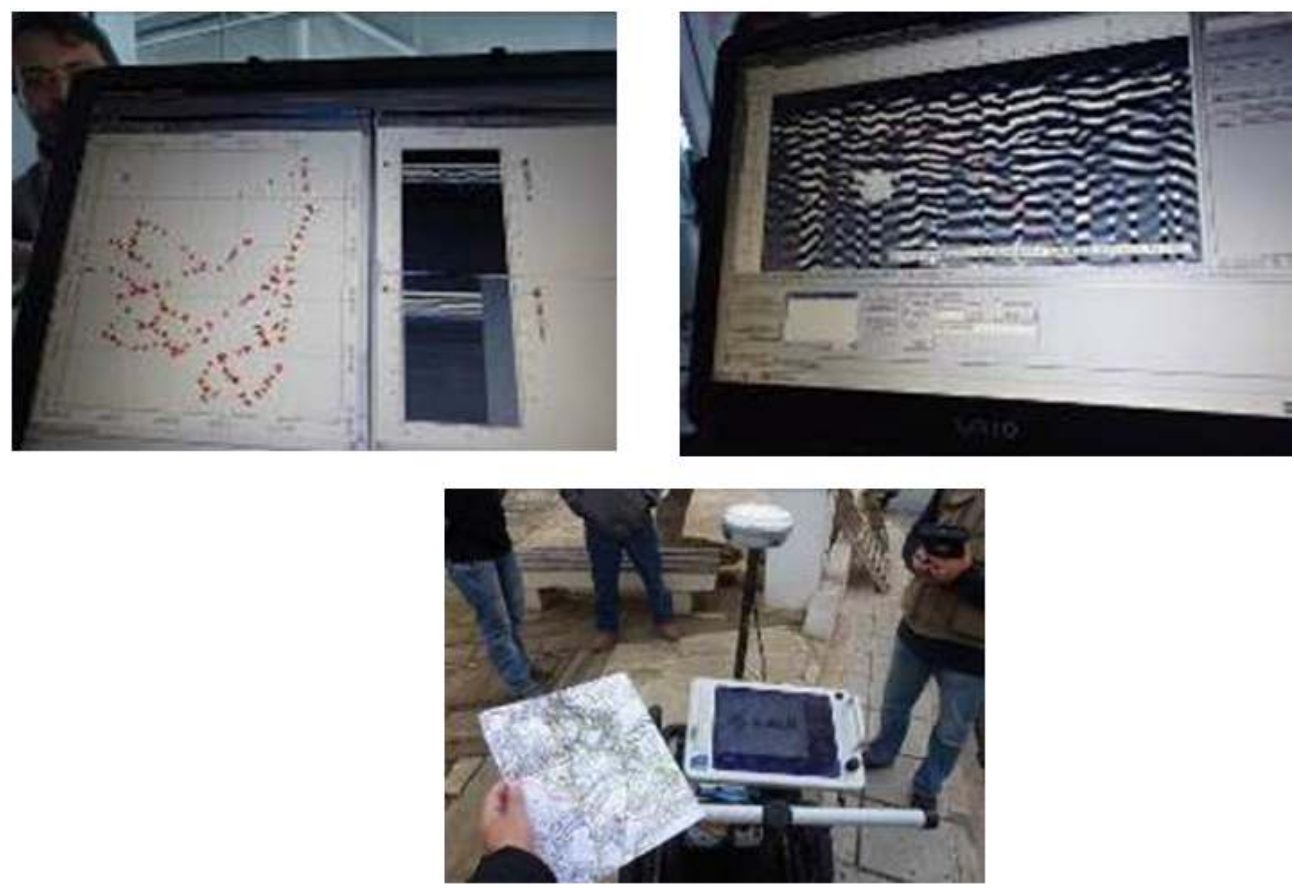

Figure 3. study, mapping and development of a digital imprint of an existing selected water supply network 


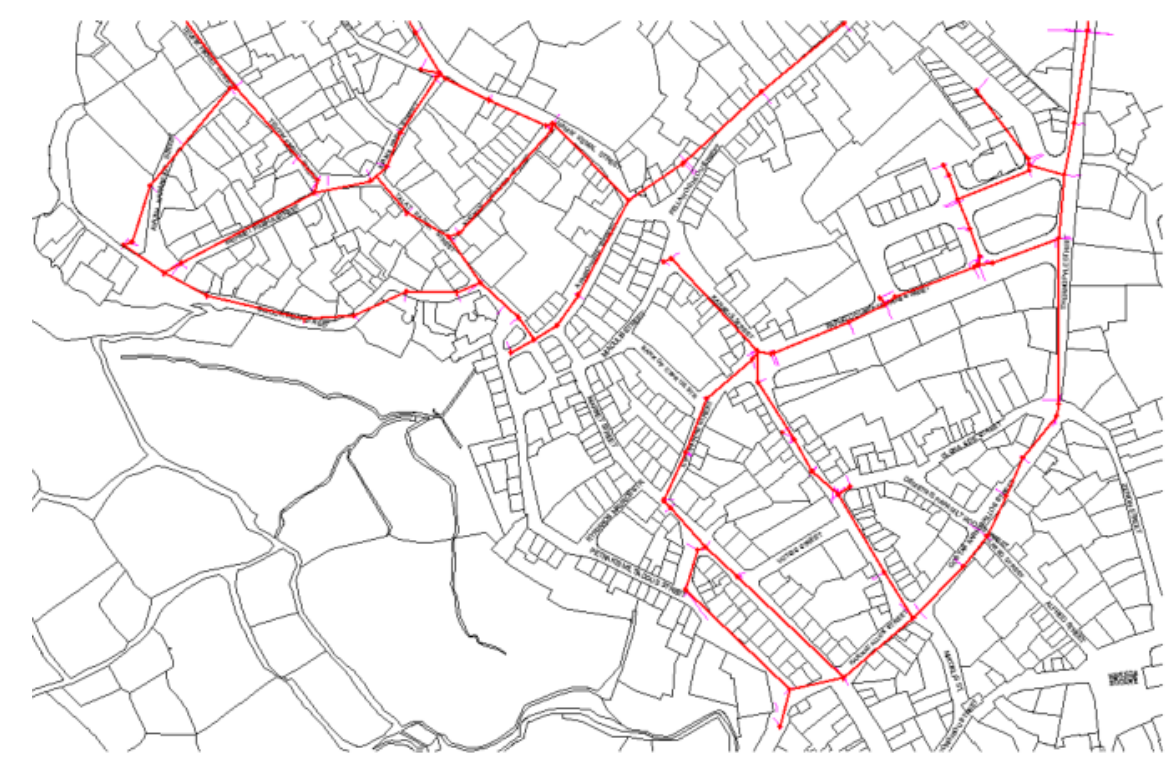

Figure 4. The water network following the GPR survey

GIS was used to develop a comprehensive management system of the information, including cartographic and quantitative data, as well as text. Maps from Paphos Municipality depicting existing buildings, streets, etc. were used in creating the digital map. The use of the radar scanner permitted the imaging of all required information regarding the existing water supply pipes, including altitudes, grading, location of other services, diameters, etc. Satellite data of the region of Paphos Municipality, including Quickbird, IKONOS, Landsat TM or SPOT satellite images, will be used to retrieve the present conditions. The capturing of satellite data at any moment in time using remote sensing techniques can provide the current construction development and, therefore, the immediate water supply needs in the municipality. In conjunction with the maps and ground measurements, it will be possible to develop an accurate digital imprint.

The acquired information will be organised in a GIS system, thereby allowing the creation of maps and their analysis at different "layers", including the water supply network, buildings, water supply elements, geographic information, features of the network's systems, etc. The basic structure of the layers is described as follows:

The first layer depicts the connections of the pipes to the buildings, including information relating to serviced flowmeters, the main input pipe, the relevant dimensions of the pipes, etc.

The second layer depicts the pipes of the network. It includes information on the geometrical elements of the excavation where the pipe is located, features of the wells, the length of the pipe, altitudes of the pipes determining their grading, etc. 
The third layer will depict the pumping stations of the selected network and will include, in text form, all the features of the pumping station such as supplies, pressures, features of the systems comprising the pumping station such as pumps, valves, flowmeters and relief systems, etc.

The fourth layer will depict the reservoirs together will all the junctions/joints of the pipes and will include a description of all the features of the reservoirs.

The fifth layer will be the type of material of the pipe network, the diameter, the depth of the network, and the installation year. Moreover, attribute tables regarding water consumption, flow, water leakages records etc. will be included.

The sixth layer will be used as a background layer from cadastral maps, elevation, etc.

The seventh layer will be the results of the field study of the radar measurements that will be surveyed by GPS technology.

Finally all the retrieved information that are available through the acquired software regarding surveying, analysis, management, processing, will be inserted in the GIS database (Figure 5). The GIS system will be flexible, allowing the addition of any layer considered necessary for the better management of the Project information. It must be noted that depending on the results of the initial study of the networks in Paphos Municipality, the final structure of the digital imprint as well as necessary information to be contained therein will be decided, in order to proceed with an accurate modeling of the representative network.

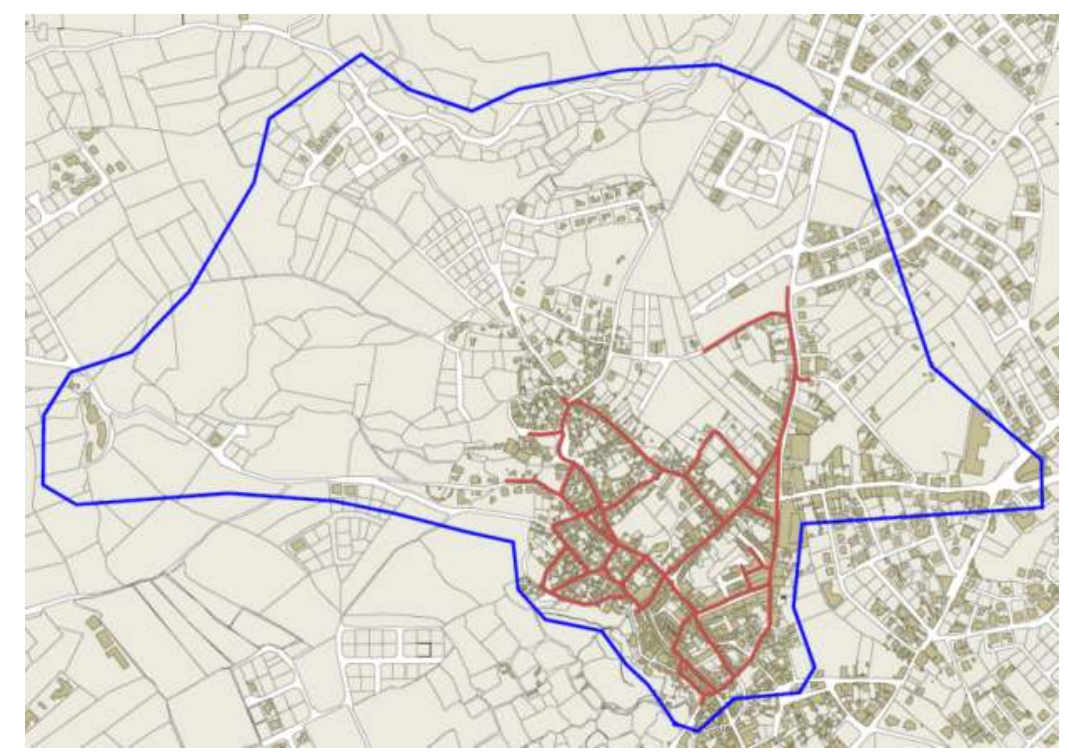

Figure 5. Area of interest, including the GPR water pipe network survey 


\section{Distribution network}

The main consideration in the design and evaluation of a water distribution system is the ability of the network to supply consumers with water of adequate quantity and quality, for the expected loading conditions during its lifetime. A reliable water distribution system could perform within specified limits in both normal and abnormal conditions, such as breaks in pipes, mechanical failure of pipes, valves, and control systems, power outages, malfunction of storage facilities and inaccurate demand projections (T. Akdoğan, 2005). Several analytical methods exist, that lead to the calculation of surrogate - based measures of reliability, which take into account the reliability of every mechanical part of the network and statistical distribution of nodal demands and loading scenarios (figure 6). Since these methods require full knowledge of the network's layout and function, stochastic simulation methods for the estimation of network reliability are often preferable, as they can provide flexibility in the types of network elements that can be included in analysis (Wagner et al., 1988), resulting in a more realistic estimation of the network reliability. The water supply network is evaluated using different user defined scenarios or during extended period simulations (Goulter et al., 2000).

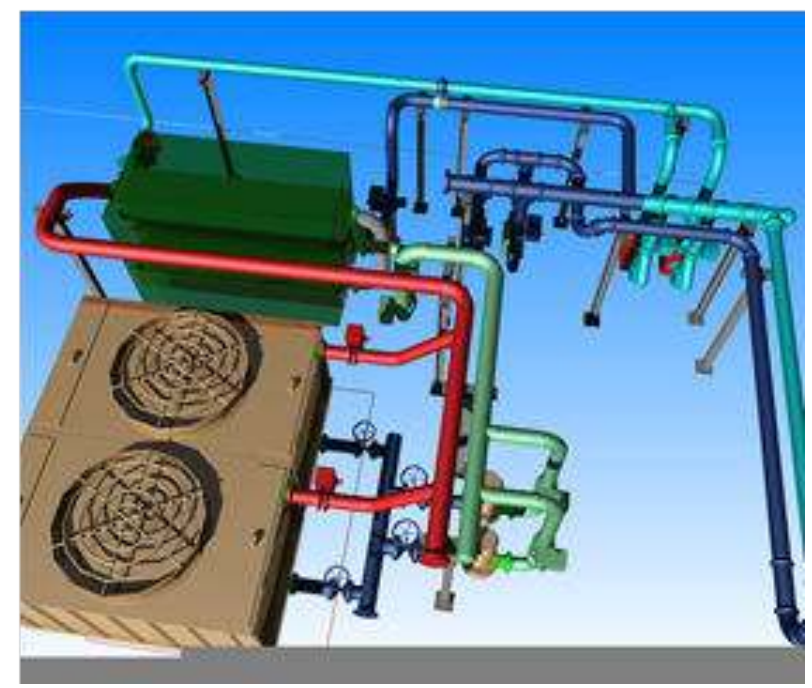

Figure 6. Typical 3D drawing of a distribution network

The local network of Moutallos district has been chosen to be modeled for the following reasons: (1) It is an old network. (2) It is a network which is closed, meaning that there is only inflow and consumption, therefore one can easily estimate the water loss due to network leakage. (3) It is limited to a small area, so that it can be modeled accurately. 


\section{Laboratory model}

The laboratory modelling was implemented in the laboratory area located at the Industrial area of Agios Silas in Limassol in Cyprus. The water supply of Moutallos comes from a storage tank which is supplied with water from a pumping station via two pumps working in parallel with flow capacities 160 and $180 \mathrm{~m} 3 /$ hour respectively. The water supply to the laboratory constant head tank was implemented by a pump of maximum capacity $350 \mathrm{~m} 3 /$ hour, which may vary using an AC driver to control the rpm of the pump motor, thus varying the flow rate delivered.

The water supply network that was designed included a constant head tank with volume of $25 \mathrm{~m} 3$, a storage tank of $1000 \mathrm{~m} 3$ located in the basement area, pipes of 3, 6 and 8 inch diameters, a pump with motor and decompression valve, analog valves for flow control and local loss introduction, flow meters, piezometers, thermometer, and hand valves for manual control of the network (Figures 7-15). All these devices, except the hand valves, can be controlled and recorded electronically. To simulate the reservoir that supplies water to the Municipality of Pafos (Moutallos area) with gravity, a constant head tank was constructed that can supply the pipe network with $9 \mathrm{~m}$ pressure head. Thus, keeping the reservoir head constant via a return overflow to the storage reservoir, experiments and computer simulations were conducted to manipulate the flow using the different valves according to the desired scenario.

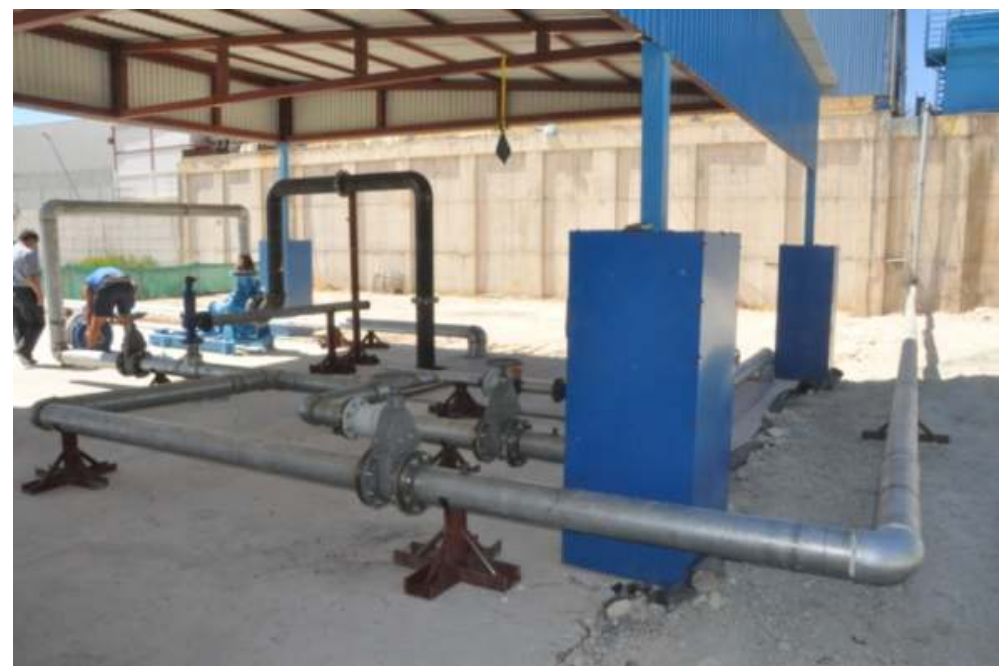

Figure 7. Photo of a part of the pipe network as it has been constructed 


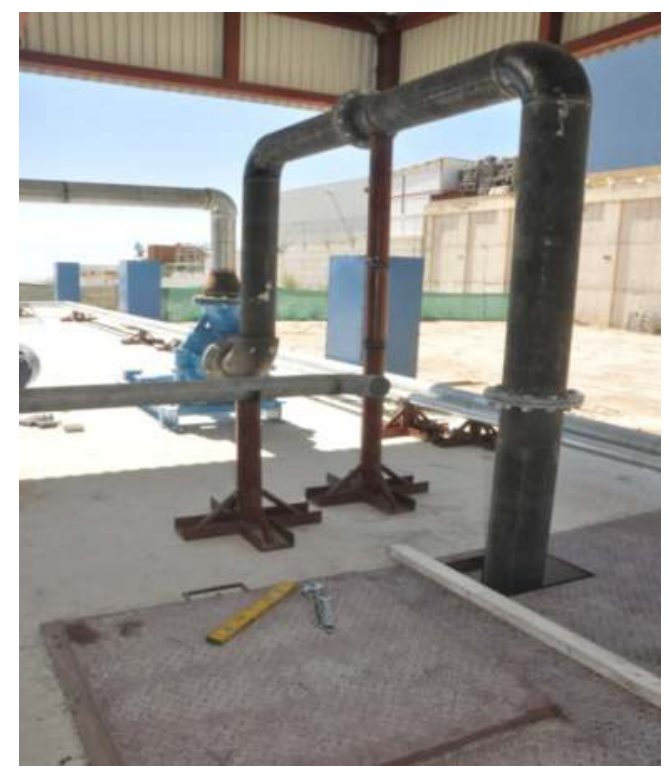

Figure 8. Pipe network during construction
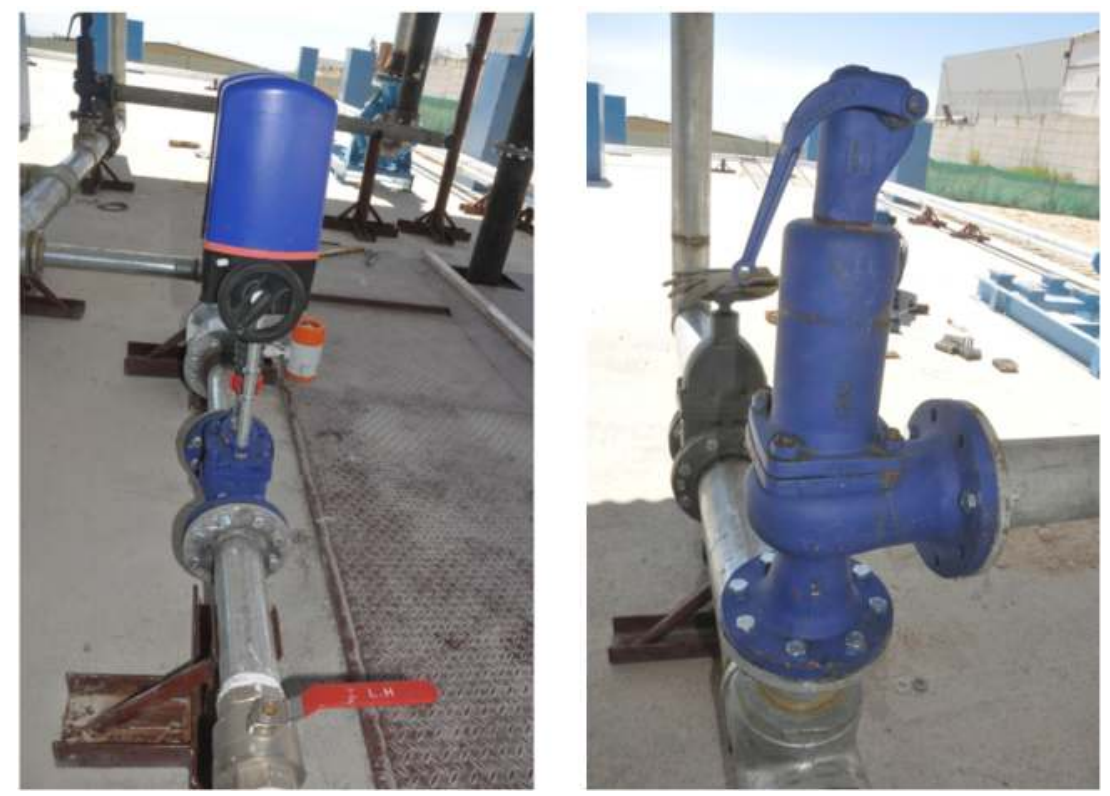

Figure 9. Analog valve (left) and pressure relief valve (right) 


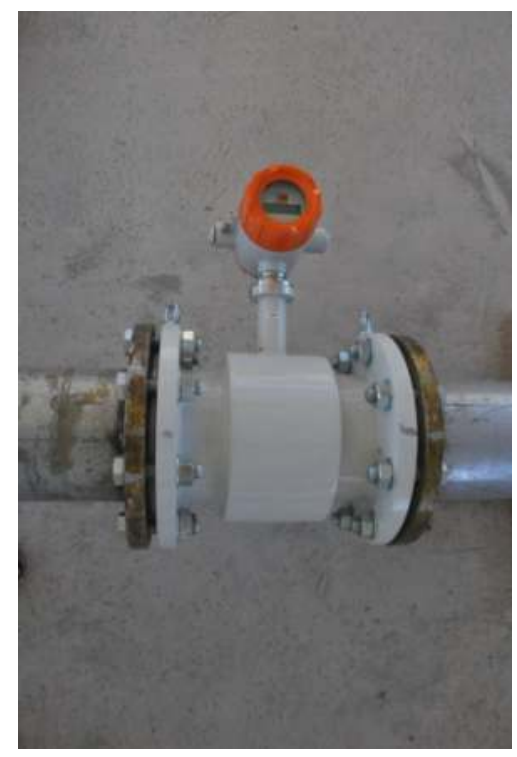

Figure 10. Digital flowmeter

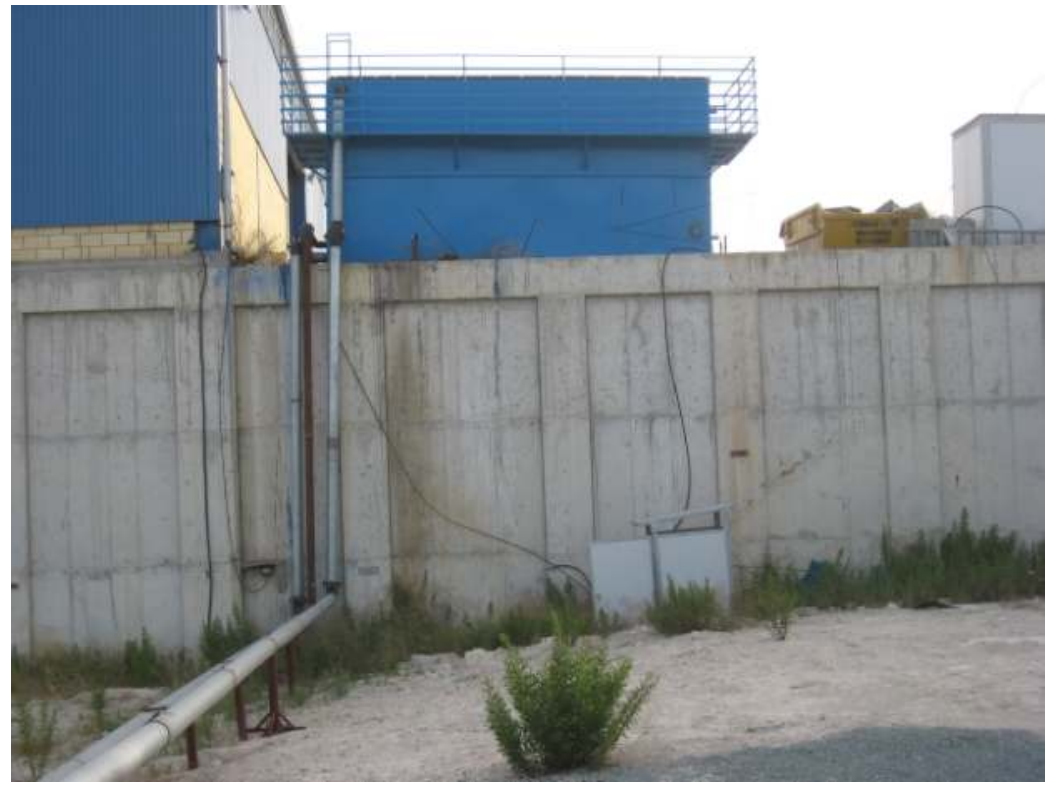

Figure 11. Constant head tank 

Water Supply Networks

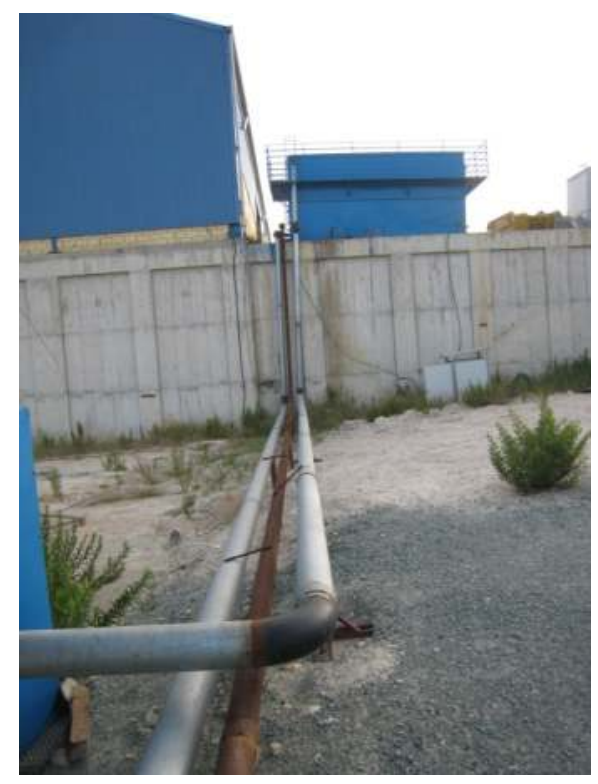

Figure 12. Constant head tank, connection to the experimental network

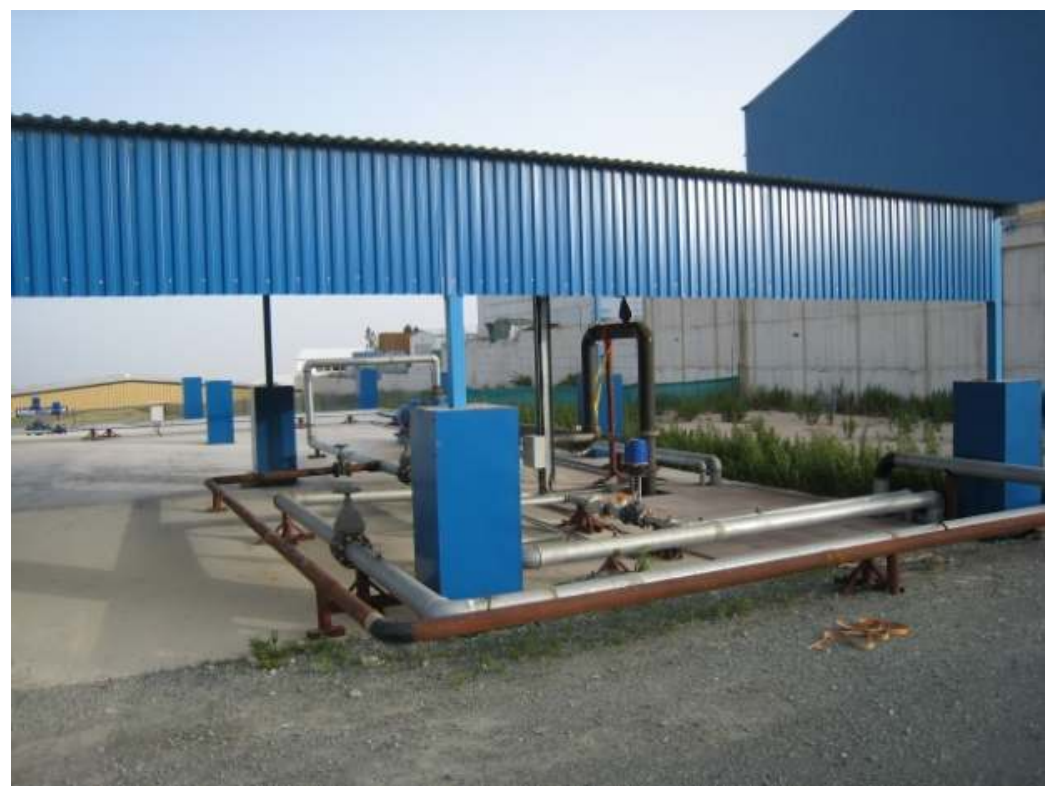

Figure 13. Overview of the pipe network 


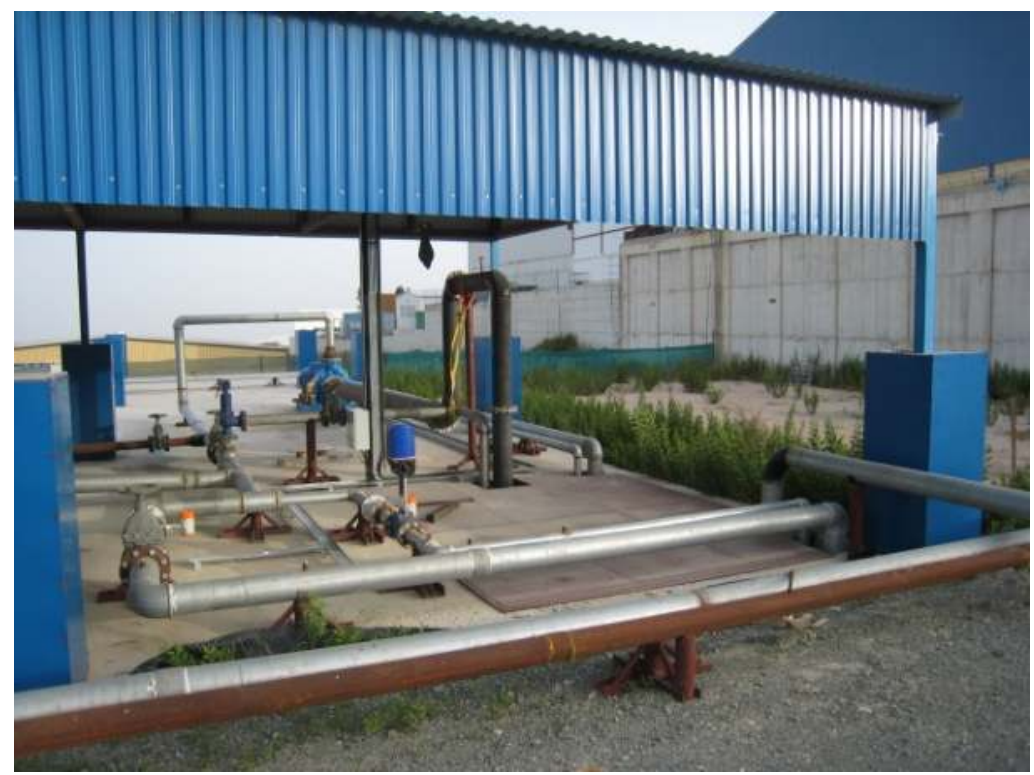

Figure 14. Overview of special network items such as bends, junctions, etc.

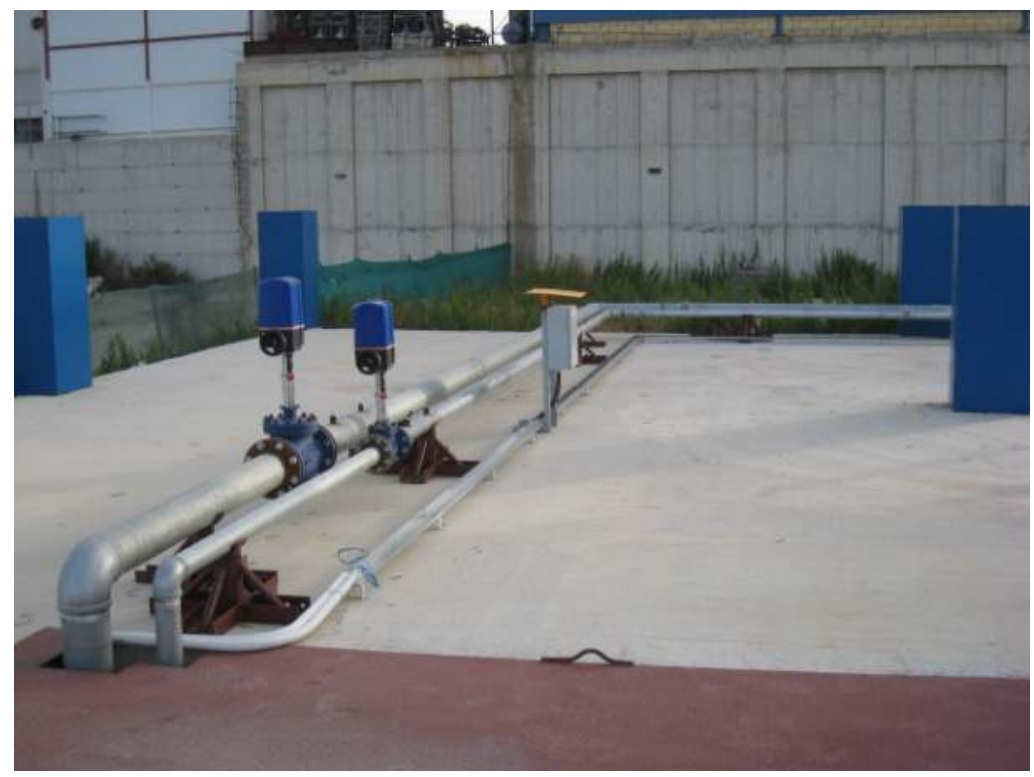

Figure 15. Long straight pipe segments where the friction losses as measured. 
Two separate flow networks were constructed. The first was supplied from the constant head tank with hydrostatic pressure of nine meters. The second was connected to a $75 \mathrm{KW}$ pump which is controlled by an AC Driver so that variable flow conditions can be applied to the network. In the second case, the consumption of electricity as a function of the load applied to the network was able to be recorded. The two flow networks have a length of $100 \mathrm{~m}$ each and are made of 3 and 6 inch pipes respectively. They can be used separately or they can be combined to one system of pipes with two different diameters. In both networks measurements can be made at several points, such as inflow discharge using flowmeters, pressure measurement along a straight pipe, at bends, at a change of diameter, etc for evaluating the friction (linear) and local energy loss of the pipe network that can be used in Moutallos network modeling via Epanet.

In the experimental pipe network, multiple sensors have been installed such as electronic manometers ( 9 pieces), electronic thermometers ( 8 pieces), magnetic-inductive flowmeters (2 pieces) torque meter ( 1 piece), ammeter (1 piece). They were all connected to a data acquisition system on a computer where the transmitting signal can be sampled in real time, in order to create a computer model of the pipe network.

In addition to the water supply to the pipe network from the constant head tank which is controlled by valves, the network was also supplied with the desired flow rate using the variable speed ACDRIVER motor of the pump, thus increasing the pipe network to the desired pressure as well. The energy losses of the whole network can be estimated using the power consumption data of the pump, which can be recorded using the data acquisition system installed in the facility.

The energy loss along each pipe (friction losses) and at special items as bends, junctions, pipe expansion or contraction, valve, etc. (Figure 14 and 15) can be estimated from the pressure difference measured at the two ends of the pipe or the special part of interest as a function of the flowrate. The piezometers have been installed at least 10 to 15 pipe diameters away from changes in the flow direction, so that the flow at the pipe section where the pressure is measured is uniform and not affected by secondary flow.

\subsection{Pipe aging}

One of the problems in the computer modelling of the pipe network is the aging of the pipes in Moutallos area. The age of the simulated network played an important role in the calculation, since the accumulation of salts may reduce the pipe diameter and also increase the roughness. Aging of the network can be obtained by keeping the pipe diameters the same while increasing the roughness in order to obtain the same friction loss as the actual aged pipe. Pipe aging can be measured through estimation of the discharge using some direct (volumetric) or indirect methodology in approximately $10 \mathrm{~m}$ long pipe segments for each pipe diameter used in Moutallos, along with the corresponding energy (pressure) loss. Thus, actual friction loss can be estimated by in-situ measurements along a straight pipeline, by recording the flow rate and the pressure loss simultaneously over a distance where there is no water supply to nearby houses during data acquisition. This is usually performed to as many pipes as the ages of which appear in the network. For example, if 6 inch pipes were installed in the network 35, 20 and 8 
years ago, then three measurements should performed, for the pipe of every age, so that estimations of the pipe roughness variation over the years (35, 20 and 8).

\subsection{Flowrate estimation}

The range of flow rates used in each pipe to be modelled can be deduced from the real flow rates that may occur in the network to be modelled. Thus, from the computer model of the Moutallos water distribution network where the water demand at each node has been estimated properly, the instantaneous minimum as well as the maximum demands for the area under consideration, thus estimating the regime of the discharge magnitude that is possible to occur in each different pipe diameter. To date, the experiments have been delayed due to the electrical connections of the sensors that have been installed in the pipe network with the data acquisition system, as well as the implementation of the proper data acquisition module in the LabView software environment which has been chosen to be used. The experimental pipe network has been tested properly and it is operational.

\section{Methodology}

The pipe network of Moutallos is modelled and solved in the commercially used EPANET software platform (Figure 16). The method used in EPANET to solve the flow continuity and headloss equations is called "Gradient Method" (Todini and Pilati, 1987 and Salgado et al., 1988). The method is thoroughly described in Epanet User's Manual (Rossman, 2000). Epanet can perform single or extended period analysis modelling of the hydraulic and water quality behavior of pressurized pipe networks that consist of pipes, nodes, valves, and storage tanks or reservoirs. EPANET's Windows user interface provides a visual network editor that simplifies the process of building piping network models and editing their properties and data. Color-coded network maps, data tables, and contour plots and other reporting and visualization tools assist in interpreting the results of a network analysis.

The water distribution network is modelled in Epanet and stochastically analyzed using Epanet Programmer's Toolkit. EPANET and its Programmer's Toolkit have been developed by the Water Supply and Water Resources Division of the U.S. Environmental Protection Agency's National Risk Management Research Laboratory, and are both freely available in the internet.

The process to built the network using the Epanet user interface is as follows:

The existing network layout plan was loaded as background map.

Tanks and nodes of the network were placed. Nodes are located in the junctions, in dead-ends of the network and where pipe diameter or material changes. Required information for every node is its elevation and base demand, and additionally initial water level for tanks.

Pipes connecting nodes based on the network layout were added. In Property Editor, the length, diameter and roughness for every pipe were entered. 


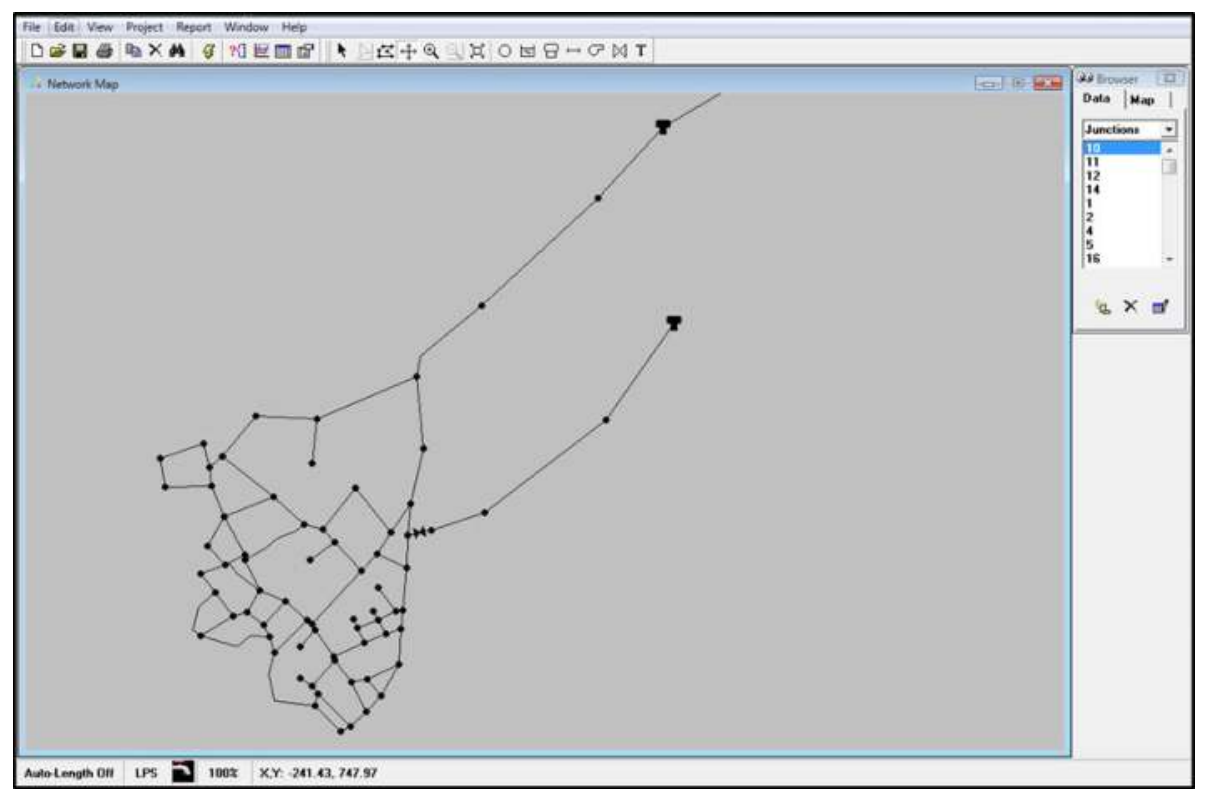

Figure 16. Model of pipe network of Moutallos in Epanet environment

The Darcy - Weisbach equation was selected as default formula for linear headloss calculations.

Project's data were exported to a text file (.inp), so that EPANET can run as a console application.

\section{Results}

The HydroGIS laboratory provides a model that is used to simulate various water supply networks. A methodology was created for detecting and adapting critical parameters of the mathematical models (e.g. surface roughness coefficient of pipes etc), based on actual experimental measurements of the flow field in corresponding hydraulic models. Detailed experimental verification of the computational results and the development of knowledge for selfregulation of pumps and valves were examined to satisfy the supply needs in conjunction with the uniform pressure distribution in the water supply network. In this way, guidelines will be developed which could form the basis for developing a user-friendly network simulation software, able to make up for the lack of communication between the different sciences involved in developing/designing and managing water supply networks.

The aim of the project is to utilize scanning and 3D spatial representation to develop a GIS platform for managing all information required, including maps, satellite imaging, 3D scans, network system components and others. A methodology is being developed regarding the 
critical parameters required for hydraulic models, and is being tested in the HydroGIS laboratory. Based on the digital imprint of the selected network, construction drawings of the network were modeled and included all the necessary information of the piping and locations of all piping components, fittings and configurations. By using the HydroGIS laboratory, the assembled network with all its necessary components process of "logical" construction of the piping were modeled in real life in order to identify the components that need to be replaced in order to reduce the water leakages in the network. Since the pipe network has been modeled, over 100 computer simulations of the network have been performed. From these simulations, node demands were estimated from yearly consumption. The network reliability is reduced for increment in hourly demand greater than $20-30 \%$ and CV $15-20 \%$. However, more measurements are needed for more accurate design. As well, laboratory data regarding local or friction losses for different types of pipes (if available), can be applied in future pipe network modelling.

\section{Acknowledgements}

This Chapter is an extended version of the paper "The use of GIS for supporting the experimental representation of the selected supply network in the Pafos municipality: the HydroGIS Lab" presented at the Second International Conference on Remote Sensing and Geoinformation of the Environment (RSCy2014), 7-10 April, 2014. [15] The results reported here are based on

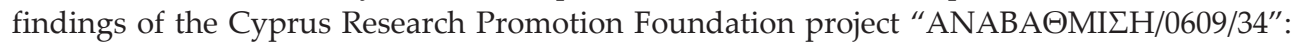
Upgrade of the hydraulics laboratory for the modeling of water supply networks \& design and operation optimization study. The project is co-funded by the Republic of Cyprus and the European Regional Development Funds of the EU.

\section{Author details}

Kyriacos Themistocleous, Ploutarchos Evlogimenos, Athos Agapiou and Diofantos G. Hadjimitsis*

*Address all correspondence to: d.hadjimitsis@cut.ac.cy

Department of Civil Engineering and Geomatics, Faculty of Engineering and Technology, Cyprus University of Technology, Cyprus

\section{References}

[1] Akdogan, T.. Design of water distribution system by optimization using reliability considerations [Dissertation]. Middle East Technical University. 
[2] Allred, B.J., Daniels, J.J. and Ehsani, M.R.. Handbook of Agricultural Geophysics. CRC Press. 2008.

[3] Crocco, L., Soldovieri, F., Millington, T. and Cassidy, L.. Bistatic tomographic GPR imaging for incipient pipeline leakage evaluation. Progress in Electromagnetics Research, 2010. PIER: pp. 307-321.

[4] Demirci, S., Yigit, E. Eskidemir, I.H. and Ozdemir, C.. Ground penetrating radar imaging of water leaks from buried pipes based on back-projection method. NDT $\mathcal{E}$ E Internation, 2012. 47: pp. 35-42.

[5] Dong, L., Carnalla, S.and Shinozuka, M.. GPR survey for pipe leakage detection: experimental and analytical study, in:Gyekenyesi, A.L. (eds.). Proceedings of the SPIE 8347. SPIe. 2012. article id 83470F.

[6] Eyuboglu, S. Mahdi, H. and Al-Shukr,i H.. Detection of water leaks using ground penetrating radar [Internet]. 2004. Available from: http://www.dot.state.fl.us/statematerialsoffice/geotechnical/materials/eyuboglu-mahdi-alshukri.pdf

[7] Gamba, P. and Lossani, S.. Neural detection of pipe signatures in ground penetrating radar images. IEEE Transactions on Geosciences and Remote Sensing, 2000. 38(2)

[8] Goulter, I., Walski, T.M., Mays, L. Sekarya, A.B.A., Bouchart, R. and Tung, Y.K.. Reliability analysis for Design-Water distribution systems handbook. 2000.

[9] Hadjimitsis, D.G., Agapiou, A., Themistocleous, K., Toulios, G., Perdikou, S. Toulios, L. and Clayton, C.. Detection of water pipes and leakages in rural water supply networks using remote sensing techniques. 2013. doi: isbn 978-953-51-1152-8

[10] Lambot, S, Slob, E.C., Chavarro, D., Lubszynski, M. and Vereecken, H. . Measuring soil surface water content in irrigated areas of southern Tunisia using full wave inversion of proximal GPR data. Near Surface Geophysics, 2008. 16: pp. 403-410.

[11] Rossman, L.A.. EPANET Programmer's toolkit manual. . Cincinnati, Ohio: Watter Supply nad Water Resources Division, National Risk Management Research Laboratory, US Environmental Protection Agency. 2000.

[12] Slagado, R., Todini, E., and O'Connel, P.E.. Comparison of the gradient method with some traditional methods for the analysis of water supply distribution networks, in:Proceedings of the International Conference on computer applications for water supply and distribution. 8-10 September, 1987. Leicester Polytechnic, UK. Leicester, UK.: Leicester Polytechnic. 1987.

[13] Todini, E. and Pilati, S.. A gradient method for the analysis of pipe networks, in:Proceedings of the International Conference on computer applications for water supply and distribution.. 8-10 September, 1987. Leicester Polytechnic, UK.. Leicester, UK.: Leicester Polytechnic. 1987. 
[14] Wagner, J.M., Shamier, U. and Marks, D.H. . Water distribution reliability: simulation methods. Journal of water resources planning and management, 1988. 114(3): pp. 276-294.

[15] Themistocleous, K., Evlogimenos, P., Agapiou, A., Theodorou, M., Demetriades, C. and D.G. Hadjimitsis. The use of GIS for supporting the experimental representation of the selected supply network in the Pafos municipality: the HydroGIS Lab.//Proc. SPIE9229, 92291X, Second International Conference on Remote Sensing and Geoinformation of the Environment (RSCy2014), 7-10 April, 2014. doi:10.1117/12.2069517. 
